\title{
Number of Tebuconazole Applications for Maximizing Disease Control and Yield of Peanut in Growers' Fields in Alabama
}

\author{
K. L. Bowen, Associate Professor, A. K. Hagan, Professor, Department of Plant Pathology, and J. R. Weeks, As- \\ sociate Professor, Department of Entomology, Auburn University, Auburn, AL 36849
}

\begin{abstract}
Bowen, K. L., Hagan, A. K., and Weeks, J. R. 1997. Number of tebuconazole applications for maximizing disease control and yield of peanut in growers' fields in Alabama. Plant Dis. $81: 927-931$

Disease and yields of peanut were monitored in growers' fields treated with zero, one, two, three, and four applications of tebuconazole. Yields ranged from 1,918 to $6,891 \mathrm{~kg} / \mathrm{ha}$ and averaged $4,319 \mathrm{~kg} / \mathrm{ha}$ over eight locations in 3 study years. Defoliation caused by peanut leaf spots (Cercospora arachidicola and Cercosporidium acutatum) and incidence of southern stem rot (Sclerotium rolfsii) were inversely related to number of tebuconazole applications, while yield was directly related to number of tebuconazole applications. Average yields with zero, one, two, and four tebuconazole applications (each application at $0.25 \mathrm{~kg}$ a.i./ha) were 3,609, 4,088, 4,526 , and 4,868 kg/ha, respectively. Data from each location were best modeled by quadratic equations allowing determination of numbers of tebuconazole applications for minimal disease and maximal yields. Calculated spray numbers indicate that between three and four applications of tebuconazole is best for disease control and yield maximization.
\end{abstract}

Additional keywords: Arachis hypogaea, groundnut, white mold

One of the more important diseases of peanut in the southeastern United States is southern stem rot (SSR), caused by Sclerotium rolfsii Sacc. SSR is a common and often destructive disease of peanut, causing annual losses in Alabama in excess of $5 \%$ of anticipated yields $(4,14,18)$. Until recently, fungicides were not highly efficacious against SSR. Management of this disease was obtained primarily through cultural methods, including crop rotation. At the farm level, however, cultural control methods were only partially effective against SSR $(13,19)$.

In 1994, the sterol demethylation inhibiting (DMI) fungicide, tebuconazole, was labeled for use on peanut for the control of SSR (8). While it is highly efficacious against SSR, concerns have been expressed about the development of resistance in the fungi that cause early and late leaf spots of peanut (Cercospora arachidicola S. Hori and Cercosporidium acutatum (Berk. \& M.A. Curtis) Deighton, respectively) to the use of DMI fungicides $(6,7)$. To avoid disease control failures due to resistance,

Corresponding author: K. L. Bowen

E-mail: kbowen@acesag.auburn.edu

Alabama Agricultural Experiment Station System Journal Series No. 18-975775.

Accepted for publication 2 May 1997.

Publication no. D-1997-0527-06R

(C) 1997 The American Phytopathological Society one strategy is to use a nonsterol fungicide prior to and following applications of the DMI fungicide (6).

This strategy to avoid DMI fungicide resistance development may fit well with the spray program for control of leaf spot diseases of peanut. For control of peanut leaf spot diseases, the initial application of the non-DMI protectant fungicide, chlorothalonil, is labeled for 30 to 40 days after planting (DAP), with repeat applications every 10 to 14 days. If the spray program for leaf spot diseases involves seven chlorothalonil applications, tebuconazole (Folicur 3.6 F label, Bayer Corp., Kansas City, MO) is labeled for application in a four-spray block on the third, fourth, fifth, and sixth spray dates.

Tebuconazole, which reduces the incidence of SSR as well as the severity of peanut leaf spot diseases, is suited for use in a weather-based advisory system (6). Weather-based advisories for scheduling fungicide applications may reduce spray numbers, thereby improving crop profitability (12). Recent changes in the USDA farm bill included reduced support prices for quota peanuts, increasing the value of efforts to minimize production costs. A key concern among growers is the relative cost versus benefit of each of the four tebuconazole sprays of the recommended block spray program (2). The purpose of this study was to evaluate numbers of tebuconazole applications and determine the number needed for optimal peanut crop management in Alabama peanut fields.

\section{MATERIALS AND METHODS}

Field sites and treatments. In April of 1991, 1992, and 1993, tests were established in two to three growers' fields with a moderate to severe history of SSR damage. In each year of the study, one of the selected fields had been planted continuously to peanut for at least 3 preceding years (locations designated GG 91, HNS 92, and WSS 93) (Table 1). One additional field in 1991, and two fields in both 1992 and 1993, had been planted to peanut for 2 consecutive years (preceded by corn at all remaining locations). Cropping patterns had been practiced by cooperating growers generally for 10 or more years. Locations SLM 91, SLM 92, WLM 93, and WSS 93 were irrigated fields, which received supplemental irrigation water to total $2.54 \mathrm{~cm}$ of water per week or more as needed. Fields were located throughout the peanut growing region of southeast Alabama in Henry, Houston, Dale, and Pike counties. Soil at all sites was a sandy loam with $<1 \%$ organic matter.

Field sites were conventionally tilled and planted (19) to cv. Florunner peanut by cooperating growers. At each field site, four to six replications of a randomized complete block design were delimited. Individual treatment plots were $15.2 \mathrm{~m}$ in length, consisting of two rows of plants. Cooperative growers followed a leaf spot control program consisting of six to eight chlorothalonil applications (1.2 kg a.i./ha) at 2-week intervals (19). Chlorothalonil applications began approximately 30 DAP. Treatments consisted of varying numbers of tebuconazole applications (Folicur 3.6F at $0.25 \mathrm{~kg}$ a.i./ha) in addition to growerapplied chlorothalonil. In 1991, five treatments were applied at two field locations, including one, two, three, and four tebuconazole applications and a chlorothalonilonly control. In 1992 and 1993, treatments were one, two, and four applications of tebuconazole and a chlorothalonil-only control. At every location in each year, single applications of tebuconazole were made approximately 15 July (75 DAP). For the two-spray program, tebuconazole was applied approximately 15 and 30 July (75 and $90 \mathrm{DAP}$ ). The first tebuconazole application in the block of three or four was made on approximately 60 DAP (1 July), and subsequent applications were made at 14-day intervals (Table 1).

Characterization of peanut pests. Defoliation, ascribed to peanut leaf spot dis- 
eases, was assessed in plots approximately 1 week prior to inversion. Defoliation was assessed by arbitrarily selecting 10 plants in each plot and removing their central stems at the soil line. On each stem, leaflets present and leaf nodes were counted. Number of leaf nodes times four was used to determine the total possible leaflet numbers, and the number of defoliated leaflets (defoliation) was expressed as the percentage of total possible leaflets (9).

Plants were inverted at maturity, allowed to dry for 3 to 5 days, then harvested. Within each plot, incidence of SSR was determined in the windrow by counting the number of SSR disease foci in two rows of the inverted crop (14), for a maximum of 31 sites per plot. A disease focus was defined as up to $30-\mathrm{cm}$ row-length that consisted of any number of adjacent dead plants with mycelial mats or sclerotia (14).

Weather data were collected from the National Weather Service monitoring station at the Wiregrass Substation of the Alabama Agricultural Experiment Station near Headland, in Henry County. This site is considered central to Alabama's peanut production area, and environmental data collected there reflect prevailing weather patterns.

Data analysis. Due to the quantitative nature of treatment levels (zero, one, two, three, and four applications of tebuconazole), data from each study year and location were subjected to regression. Measured variables were the dependent variables in regression analyses, and number of tebuconazole applications was the independent variable. Linear, quadratic, and exponential models were fit to the data. Coefficients of determination $\left(r^{2}\right)$ and the significance of each model $(P)$ were compared to determine which of the models best fit the data. Yield was also regressed on defoliation, incidence of SSR, and number of tebuconazole applications to determine which variables accounted for most of the variation in yield.

Optimal numbers of applications of tebuconazole were determined using standard production and profit maximization techniques $(3,15)$. Regression models of number of tebuconazole applications on each of the measured variables were differentiated and solved for zero. These solutions represent the number of tebuconazole applications for minimizing defoliation and incidence of SSR, and maximizing yield.

\section{RESULTS}

Average monthly temperatures and total precipitation for May through September were $25.6^{\circ} \mathrm{C}$ and $65.8 \mathrm{~cm}$ in $1991,24.7^{\circ} \mathrm{C}$ and $49.3 \mathrm{~cm}$ in 1992 , and $25.4^{\circ} \mathrm{C}$ and 37.1 $\mathrm{cm}$ in 1993. Rain events of $\geq 0.25 \mathrm{~cm}$ occurred during 47 days in 1991, 36 days in 1992, and 28 days in 1993. The 1993 growing season was hot and dry throughout the region, with rainfall for May through September totaling $23.6 \mathrm{~cm}$ less than 30-year normals at the Wiregrass Substation for those months (1).

Treatment effects on defoliation. Over the eight locations, average defoliation was incrementally reduced by $1.3,3.9$, and $2.1 \%$ with the first, second, and third or fourth tebuconazole applications, respectively. Trends among locations were not observed in levels of defoliation or treat-

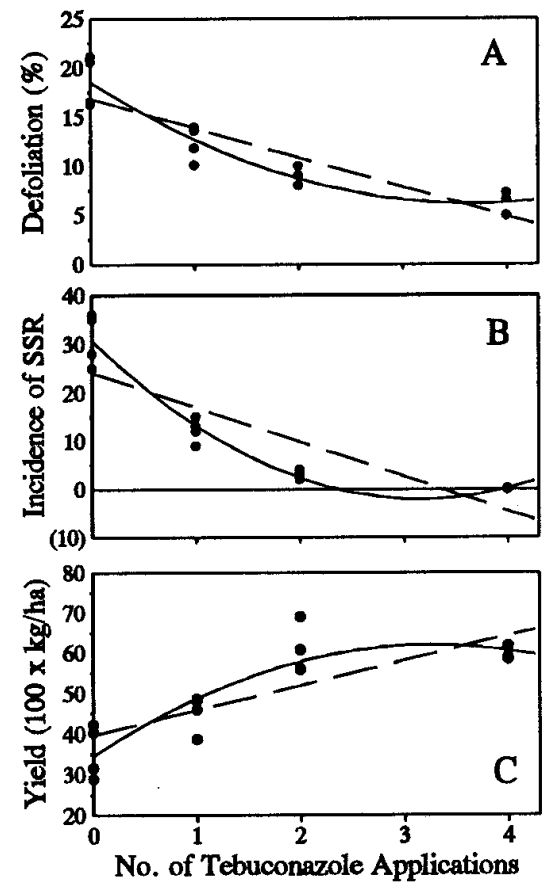

Fig. 1. Data points and regression models for (A) percent defoliation $(d)$, (B) incidence of southern stem rot (SSR) in $30.5-\mathrm{m}$ row $(s)$, and (C) yield ( $\mathrm{kg} / \mathrm{ha})(y)$ with zero, one, two, and four applications of tebuconazole $(t)$. Data from location designated MRH 92. A, Defoliation: linear model, $d=16.84-3.00 t, r^{2}=0.79, P=$ 0.0001 ; quadratic model, $d=18.51-6.76 t+$ $0.92 t^{2}, r^{2}=0.90, P=0.0001$. B, Incidence of SSR: linear model, $s=24.10-7.16 t, r^{2}=0.73$, $P=0.0001$; quadratic model, $s=30.65-20.72 t$ $+3.27 t^{2}, r^{2}=0.95, P=0.0001$. C, Yield: linear model, $y=3,961.6+615.3 t, r^{2}=0.65, P=$ 0.0002; quadratic model, $y=3,445.6+1,684.3 t$ $-258.1 t^{2}, r^{2}=0.81, P=0.0001$.

Table 1. Designations and descriptors for growers' field locations used in this study

\begin{tabular}{lccccccc}
\hline & & & & \multicolumn{3}{c}{ Tebuconazole spray dates $^{\mathbf{z}}$} \\
\cline { 5 - 7 } Field, year & Irrigation & Preceding crops $^{\mathbf{y}}$ & Planting date & First & Second & Third \\
\hline GG 91 & No & P-P & May 25 & July 17 & July 30 & Aug. 13 & Aug. 26 \\
SLM 91 & Yes & CR-P & May 7 & July 1 & July 16 & July 29 & Aug. 12 \\
HNS 92 & No & P-P & April 15 & June 29 & July 13 & July 27 & Aug. 5 \\
MRH 92 & No & CR-P & May 7 & June 30 & July 14 & July 27 & Aug. 4 \\
SLM 92 & Yes & CR-P & April 25 & June 30 & July 13 & July 27 & Aug. 4 \\
MRH 93 & No & CR-P & May 1 & June 30 & July 19 & July 28 & Aug. 9 \\
WLM 93 & Yes & CR-P & May 4 & July 1 & July 19 & Aug. 2 & Aug. 9 \\
WSS 93 & Yes & P-P & May 4 & July 6 & July 19 & Aug. 2 & Aug. 10 \\
\hline
\end{tabular}

y In chronological order, with P = peanuts and CR = corn; e.g., for field location SLM 91, CR-P indicates that corn was planted in 1989, followed by peanuts in 1990, with peanuts studied in 1991.

${ }^{z}$ Dates are listed for the block of four sprays. Plots receiving a single spray were treated on the second spray date. Plots receiving two sprays were treated on the second and third spray dates. Plots receiving three sprays were treated on the second, third, and fourth spray dates.

Table 2. Means for defoliation, presumably due to peanut leaf spot diseases, as measured by proportion of leaves remaining on limbs for each of eight growers' fields

\begin{tabular}{|c|c|c|c|c|c|c|c|c|}
\hline \multirow{2}{*}{$\begin{array}{l}\text { Tebuconazole } \\
\text { applications }\end{array}$} & \multicolumn{2}{|c|}{1991} & \multicolumn{3}{|c|}{1992} & \multicolumn{3}{|c|}{1993} \\
\hline & GG & SLM & HNS & MRH & SLM & MRH & WLM & WSS \\
\hline None & 44.85 & 34.85 & 35.22 & 18.62 & 28.85 & 40.62 & 30.52 & 43.22 \\
\hline One & 39.80 & 35.55 & 30.88 & 12.35 & 26.05 & 53.02 & 31.30 & 37.18 \\
\hline Two & 35.32 & 31.40 & 32.30 & 9.00 & 25.48 & 37.50 & 27.75 & 36.55 \\
\hline Three & 35.90 & 28.35 & $-^{\mathrm{z}}$ & - & - & - & - & - \\
\hline Four & 35.80 & 29.75 & 29.60 & 6.20 & 21.58 & 35.08 & 26.18 & 34.10 \\
\hline
\end{tabular}

${ }^{\mathrm{z}}$ Treatments not applied. 
ment effects in irrigated versus dryland locations (Table 2).

Quadratic models of defoliation on number of tebuconazole applications generally provided a better fit than linear (Fig. 1A) or exponential models. Regression of defoliation on number of tebuconazole applications was significant for data from seven of the eight locations $\left(P<0.10, r^{2}>\right.$ 0.30 ) (Table 3 ). From the quadratic equations, the number of tebuconazole applications that provided maximal control of defoliation was calculated for each location (Table 3). Data from three locations (SLM 91, SLM 92, and MRH 93) resulted in unrealistic solutions (solving the differential for zero did not result in an optimal solution or the number of applications was more than 20) and were dropped. Calculated maxima from the remaining locations ranged from 3.03 to 4.05 , with an average of 3.6 tebuconazole applications for maximal control of defoliation.

Treatment effects on SSR incidence. Over eight fields, the incremental reduction in average incidence of SSR was 7.8, 5.5, and 2.1 disease foci with the first, second, and third or fourth tebuconazole application, respectively. No consistency was observed in levels of SSR or treatment effects among irrigated versus dryland field sites (Table 4).

Quadratic models of the incidence of SSR on number of tebuconazole applications generally provided a better fit than linear (Fig. 1B) or exponential models. Quadratic models were significant for incidence of SSR on number of tebuconazole applications $\left(P<0.0005,0.64<r^{2}<0.96\right)$ at all eight locations (Table 5). From the quadratic equations, the numbers of tebuconazole applications for maximal control of SSR were calculated for each field location (Table 5). Optimal spray numbers ranged from 2.97 to 10.19 . Data from MRH 93 presented an unrealistic solution (number of applications was more than 10) and were dropped. The average of calculated maxima from the seven remaining locations was 3.2 tebuconazole applications for maximal control of SSR.

Treatment effects on yield. Yield from plots treated only with chlorothalonil averaged $3,579 \mathrm{~kg} / \mathrm{ha}$ across all locations. Average incremental yield increases across all locations were $596(17 \%), 397(10 \%)$, and $434(9 \%) \mathrm{kg} / \mathrm{ha}$ with the first, second, and third or fourth applications of tebucona- zole, respectively. No consistent trends were observed in yield levels or treatment effects among irrigated versus dryland locations (Table 6).

Quadratic models of yield on number of tebuconazole applications generally provided a better fit than did linear (Fig. 1C) or exponential models. Quadratic models were significant for yield on number of tebuconazole applications $(P<0.02,0.36<$ $r^{2}<0.85$ ) (Table 7) for data from seven field locations. Solving the differential for zero did not yield an optimal solution for location MRH 93. Thus, the number of tebuconazole applications resulting in maximal yield was calculated for six field locations. Calculations indicate that maximal yields were obtained with 2.82 to 4.84 (averaging 3.7) applications of tebuconazole. Comparisons of coefficients of determination from quadratic models describing the relationships between the number of tebuconazole sprays and both yield and SSR indicated that the number of tebuconazole applications accounted for more variation in SSR than in yield.

Analyses of covariance were performed to determine if the treatment effect on defoliation and SSR explained the treatment

Table 3. Regression models, coefficients of determination, and model significance, from each location, of defoliation (\%) regressed on number of tebuconazole applications $(x)$

\begin{tabular}{lccccc}
\hline Location & Quadratic model & $\boldsymbol{R}^{\mathbf{2}}$ & $\boldsymbol{P}$ & Differential & Control optimum \\
\hline GG 91 & $44.85-6.49 x+1.07 x^{2}$ & 0.81 & 0.0001 & $2.14 x-6.49$ & 3.03 \\
SLM 91 & $35.56-1.34 x-0.25 x^{2}$ & 0.53 & 0.0016 & $-0.50 x-1.34$ & NAO \\
HNS 92 & $34.60-2.35 x+0.29 x^{2}$ & 0.40 & 0.0356 & $0.58 x-2.35$ & 4.05 \\
MRH 92 & $18.51-6.76 x+0.92 x^{2}$ & 0.90 & 0.0001 & $1.84 x-6.76$ & 3.67 \\
SLM 92 & $28.59-1.90 x+0.04 x^{2}$ & 0.34 & 0.0703 & $0.08 x-1.90$ & 23.75 \\
MRH 93 & $43.69+2.35 x-1.19 x^{2}$ & 0.31 & 0.0911 & $2.35-2.38 x$ & NAO \\
WLM 93 & $30.98-1.09 x-0.04 x^{2}$ & 0.18 & NS & - & 3.45 \\
WSS 93 & $42.75-5.03 x+0.73 x^{2}$ & 0.71 & 0.0003 & $1.46 x-5.03$ & \\
\hline
\end{tabular}

y Solving the model's differential for zero does not result in an optimal solution.

${ }^{\mathrm{z}}$ Model was not significant $(P<0.10)$ and no further calculations were performed.

Table 4. Means for incidence of southern stem rot (SSR) foci, as measured by up to 30-cm length in windrow consisting of dead plants with Sclerotium rolfsii or sclerotia, for each of eight growers' fields

\begin{tabular}{|c|c|c|c|c|c|c|c|c|}
\hline \multirow{2}{*}{$\begin{array}{l}\text { Tebuconazole } \\
\text { applications }\end{array}$} & \multicolumn{2}{|c|}{1991} & \multicolumn{3}{|c|}{1992} & \multicolumn{3}{|c|}{1993} \\
\hline & GG & SLM & HNS & MRH & SLM & MRH & WLM & WSS \\
\hline None & $6.8 \mathrm{a}$ & 11.0 & 7.5 & 31.0 & 14.2 & 26.3 & 16.0 & 16.3 \\
\hline One & $1.0 \mathrm{~b}$ & 3.0 & 4.0 & 12.2 & 0.8 & 29.3 & 10.0 & 6.0 \\
\hline Two & $1.5 \mathrm{~b}$ & 1.5 & 1.3 & 3.0 & 0.5 & 6.5 & 2.0 & 5.8 \\
\hline Three & $0.5 \mathrm{~b}$ & 1.5 & $-^{\mathrm{z}}$ & - & - & - & - & - \\
\hline Four & $0.2 \mathrm{~b}$ & 0.8 & 0.5 & 0.0 & 0.5 & 1.0 & 1.0 & 1.7 \\
\hline
\end{tabular}

z Treatments not applied.

Table 5. Regression models, coefficients of determination, and model significance, from each location, of incidence of southern stem rot (loci/30.5 $\mathrm{m}$ row) regressed on number of tebuconazole applications $(x)$

\begin{tabular}{lccccc}
\hline Location & Regression equation & $\boldsymbol{R}^{\mathbf{2}}$ & $\boldsymbol{P}$ & Differential & Control optimum \\
\hline GG 91 & $6.06-4.06 x+0.67 x^{2}$ & 0.64 & 0.0002 & $1.34 x-4.06$ & 3.03 \\
SLM 91 & $10.24-6.77 x+1.14 x^{2}$ & 0.74 & 0.0001 & $2.28 x-6.77$ & $1.30 x-4.38$ \\
HNS 92 & $7.54-4.38 x+0.65 x^{2}$ & 0.67 & 0.0001 & $6.54 x-20.72$ & 3.37 \\
MRH 92 & $30.65-20.72 x+3.27 x^{2}$ & 0.95 & 0.0001 & $4.32 x-11.74$ & 3.17 \\
SLM 92 & $13.18-11.74 x+2.16 x^{2}$ & 0.83 & 0.0001 & $0.90 x-9.17$ & 10.72 \\
MRH 93 & $29.45-9.17 x+0.45 x^{2}$ & 0.73 & 0.0002 & $2.78 x-9.49$ & 3.41 \\
WLM 93 & $16.57-9.49 x+1.39 x^{2}$ & 0.88 & 0.0001 & $2.36 x-8.08$ & 3.42 \\
WSS 93 & $15.40-8.08 x+1.18 x^{2}$ & 0.74 & 0.0001 & & \\
\hline
\end{tabular}


effect on yield. None of the measured disease variables from two locations (SLM 91 and HNS 92) explained variation in yield. Analyses of covariance indicated that the treatment effect on defoliation did not explain variation in yield at any of the remaining six locations. The tebuconazole effect on SSR, however, explained a portion of the treatment effect on yield at four locations (GG 91, MRH 92, SLM 92, and WSS 93). At two locations (MRH 93 and WLM 93), the number of tebuconazole applications had a significant effect on yield, indicating an effect that is over and above the effect of tebuconazole on SSR.

\section{DISCUSSION}

This study determined the number of tebuconazole applications that provided maximal disease control or yield in growers' peanut production fields. Within each of the eight production fields, levels of defoliation, incidence of SSR, and yields were similar with two, three, and four tebuconazole applications. However, when empirical data were fit to quadratic models, calculated numbers of tebuconazole sprays for minimal defoliation and SSR, and maximum yield averaged 3.0 to 4.1 applications (at $0.25 \mathrm{~kg}$ a.i. per application) over each location.

In this study, tebuconazole was oversprayed to peanuts that had been treated with chlorothalonil on 14-day intervals. These chlorothalonil applications would be expected to control defoliation that is ascribed to leaf spot pathogens of peanut (12). Therefore, tebuconazole treatments would not be expected to greatly contribute to minimization of defoliation in most years. However, one, two, and four tebuconazole applications decreased defoliation an average of 6,18 , and $24 \%$, respectively, over all eight locations compared with the no tebuconazole control.

Incidence of SSR and yield, at eight and seven locations, respectively, were significantly affected by tebuconazole. These observations agree with previously published results $(5,6,11)$. On cultivar Southern Runner, which has partial resistance to late leaf spot, tebuconazole was used in various spray regimes with chlorothalonil and weather-based advisories (6). Only fungicide regimes that included applications of tebuconazole reduced both final leaf spot ratings and SSR compared with the use of chlorothalonil only. Brenneman and Culbreath (6) also calculated linear regression models that described the relationships between number of tebuconazole sprays and SSR, yield, and seed grade. Their linear models describing yields were similar to ours (data not shown). However, curvilinear models were not fit to their data, so no conclusions could be made regarding an optimal number of tebuconazole sprays.

Cyproconazole is another DMI fungicide with efficacy against SSR in peanut. Davis et al. (10) reported that numbers of cyproconazole applications were linearly related to SSR and yield. Since the relationships they observed were linear, Davis et al. (10) concluded that a benefit will be derived even when cyproconazole spray schedules are started late in the growing season. Our results with numbers of tebuconazole applications are similar, in that linear relationships were observed; however, quadratic relationships generally provided better fit to the data. In addition, while the single- and two-spray blocks of cyproconazole were applied at 113 DAP and $96+113$ DAP, respectively, the single- and two-spray blocks of tebuconazole were applied at 75 and $75+90 \mathrm{DAP}$, respectively. A greater incremental gain in control of SSR and improved yields were observed with one and perhaps a second application of tebuconazole, but the timing of tebuconazole applications was closer to midseason.

Initial symptoms of SSR usually become evident midseason during peg and pod formation (approximately 75 DAP) (14). However, in some years, mycelial mats, sclerotia, and brown lesions can be found on limbs at the soil line within 45 DAP (K. L. Bowen, unpublished). Chemical control may be more effective if applied to peanut upon initiation of this disease. However, the conditions in which SSR is initiated and develops are not fully understood. Improved understanding of the epidemiology of SSR could improve our ability to control this disease.

Concern over the four-block spray regime for tebuconazole has been expressed due to the possible development of fungicide resistance $(2,6)$. These results indicate that between 3.2 and 3.7 tebuconazole applications $(0.25 \mathrm{~kg}$ a.i. per application) over a growing season provide maximal control of defoliation and SSR. Optimal numbers of tebuconazole applications for profit maximization were also determined (data not shown). For profit maximization calculations, three price levels were used for both the cost of a tebuconazole application ( $\$ 10$ to $\$ 14 / \mathrm{ha}$ ) and the price received for peanuts $(\$ 0.52$ to $\$ 0.65 / \mathrm{kg}$ ). Numbers of tebuconazole applications that allowed profit maximization did not differ substantially from numbers of sprays providing maximal yield, ranging from 0.29 (0.07 kg a.i./ha/year) fewer to 0.17 (0.04 $\mathrm{kg}$ a.i./ha/year) greater numbers of appli-

Table 6. Means of yield (kg/ha) for each of eight growers' fields

\begin{tabular}{|c|c|c|c|c|c|c|c|c|}
\hline \multirow[b]{2}{*}{ Treatment } & \multicolumn{2}{|c|}{1991} & \multicolumn{3}{|c|}{1992} & \multicolumn{3}{|c|}{1993} \\
\hline & GG & SLM & HNS & MRH & SLM & MRH & WLM & WSS \\
\hline Control & 4,068 & 4,877 & 3,681 & 3,573 & 4,419 & 2,381 & 3,098 & 2,535 \\
\hline One & 4,401 & 4,985 & 3,826 & 4,534 & 5,159 & 3,091 & 3,286 & 4,119 \\
\hline Two & 4,606 & 5,074 & 4,241 & 6,035 & 5,224 & 3,279 & 4,319 & 3,798 \\
\hline Three & 4,594 & 5,143 & $-^{z}$ & - & - & - & - & - \\
\hline Four & 4,555 & 5,075 & 4,241 & 6,012 & 5,535 & 5,166 & 4,569 & 4,893 \\
\hline
\end{tabular}

${ }^{\mathrm{z}}$ Treatments not applied.

Table 7. Regression models, coefficients of determination, model significance, calculated differential equation, and optima, from each location, of yield $(\mathrm{kg} / \mathrm{ha})$ regressed on number of tebuconazole applications $(x)$

\begin{tabular}{lccccc}
\hline Location & Regression equation & $\boldsymbol{R}^{\mathbf{2}}$ & $\boldsymbol{P}$ & Differential & Production optimum \\
\hline GG 91 & $4,073.3+395.2 x-70.2 x^{2}$ & 0.37 & 0.0188 & $395.2-140.2 x$ & - \\
SLM 91 & $4,867.0+161.8 x-26.7 x^{2}$ & 0.08 & NS & -82 & - \\
HNS 92 & $3,658.4+339.2 x-47.4 x^{2}$ & 0.42 & 0.0094 & $339.2-94.8 x$ & 3.58 \\
MRH 92 & $3,445.6+1,684.3 x-258.1 x^{2}$ & 0.81 & 0.0001 & $1,684.3-516.1 x$ & 3.26 \\
SLM 92 & $4,479.0+605.9 x-86.7 x^{2}$ & 0.54 & 0.0061 & $605.9-173.4 x$ & $313.3+177.4 x$ \\
MRH 93 & $2,464.8+313.3 x+88.7 x^{2}$ & 0.84 & 0.0001 & $694.5-143.6 x$ & 4.84 \\
WLM 93 & $2,979.7+694.5 x-71.8 x^{2}$ & 0.55 & 0.0059 & $944.9-211.4 x$ & 4.47 \\
WSS 93 & $2,737.3+944.9 x-105.7 x^{2}$ & 0.52 & 0.0004 & \\
\hline
\end{tabular}

${ }^{\mathrm{y}}$ Model was not significant $(P<0.10)$ and no further calculations were performed.

${ }^{\mathrm{z}}$ Solving the model's differential for zero does not result in an optimal solution. 
cations compared with calculated production maxima.

Relative to maximizing yield, the data indicate that in years similar to 1991, when levels of SSR are low and yield potential is high, fewer than three sprays of tebuconazole may be needed. Rainfall was more abundant in 1991 than in other years of this study; average temperature was similar between 1991 and 1993. In 1991, rain occurred more regularly throughout the season, and such consistent rainfall would maintain more constant soil moisture, possibly minimizing germination of $S$. rolfsii sclerotia (13). In addition, rain washes tebuconazole from foliage onto the soil surface, thereby affording better control of this soilborne fungus (Folicur 3.6 F label). Further, water is essential for maximum yield (16) and may be a factor in limiting peanut yield in the southeastern United States.

The possibility that fewer than four tebuconazole applications (each application at $0.25 \mathrm{~kg}$ a.i./ha) can provide maximum SSR control and yields is valuable information to growers and researchers. Our results support the efficacy of the fourspray block of tebuconazole for maximizing yield in most situations (since a fraction of a spray will not be applied). However, the four-spray block regime for tebuconazole, preceded and followed by chlorothalonil sprays, will only allow avoidance of the development of fungicide resistance in the foliar pathogens, C. arachidicola and $C$. acutatum. Since chlorothalonil has no effect on $S$. rolfsii, this strategy will not avoid resistance development in this soilborne fungus. These data suggest that the tebuconazole load could be reduced without a loss of efficacy for con- trol of SSR and maximization of yields, based on the amount of chemical applied. However, additional research is needed before such a recommendation can be made. Such a reduction in tebuconazole application could, in part, contribute toward avoiding development of fungicide resistance in $S$. rolfsii (17).

\section{ACKNOWLEDGMENTS}

We thank Becky Young and Tracy Mahonney for their technical support of this work. This study was supported in part by USDA Southern Regional IPM project USDA-CRS-92341036922.

\section{LITERATURE CITED}

1. Anonymous. 1993. 1993 Alabama Agricultural Experiment Station Weather Data. Agric. Weather Ser. No. 33, Auburn University.

2. Backman, P. A. 1992. Application strategies for minimizing resistance build-up to sterol inhibitor fungicide in southern peanuts. (Abstr.) Proc. Am. Peanut Res. Educ. Soc. 24:56

3. Bowen, K. L. Economics and Decision Analysis. In: Exercises in Plant Disease Epidemiology. L. Francl and D. Neher, eds. American Phytopathological Society, St. Paul, MN. In press.

4. Bowen, K. L., Hagan, A. K., and Weeks, R. 1992. Seven years of Sclerotium rolfsii in peanut fields: Yield losses and means of minimization. Plant Dis. 76:982-985.

5. Bowen, K. L., Hagan, A. K., and Weeks, R. 1996. Soil-borne pests of peanut in growers fields with different cropping histories in Alabama. Peanut Sci. 23:36-42.

6. Brenneman, T. B., and Culbreath, A. K. 1994. Utilizing a sterol demethylation inhibiting fungicide in an advisory program to manage foliar and soilborne pathogens of peanut. Plant Dis. 78:866-872.

7. Brenneman, T. B., Murphy, A. P., and Csinos, A. S. 1991. Activity of tebuconazole on Sclerotium rolfsii and Rhizoctonia solani, two soilborne pathogens of peanut. Plant Dis. 75:744-747.

8. Culbreath, A. K., Brenneman, T. B., Bondari,
K., Reynolds, K. L., and McLean, H. S. 1995. Late leaf spot, southern stem rot, and peanut yield responses to rates of cyproconazole and chlorothalonil applied alone and in combination. Plant Dis. 79:1121-1124.

9. Davis, D. P., Jacobi, J. C., and Backman, P. A. 1993. Twenty-four-hour rainfall, a simple environmental variable for predicting peanut leaf spot epidemics. Plant Dis. 77:722-725.

10. Davis, R. F., Smith, F. D., Brenneman, T. B., and McLean, H. 1996. Effect of irrigation on expression of stem rot of peanut and comparison of aboveground and belowground disease ratings. Plant Dis. 80:1155-1159.

11. Hagan, A. K., Weeks, J. R., and Bowen, K. 1991. Effects of application timing and method on control of southern stem rot of peanut. Peanut Sci. 18:47-50.

12. Jacobi, J. C., Backman, P. A., Davis, D. P., and Brannen, P. M. 1995. AU-Pnuts advisory I: Development of a rule-based system for scheduling peanut leaf spot fungicide applications. Plant Dis. 79:666-671.

13. Porter, D. M. 1984. Compendium of Peanut Diseases. American Phytopathological Society, St. Paul, MN

14. Rodríguez-Kábana, R., Backman, P. A., and Williams, J. C. 1975. Determination of yield losses to Sclerotium rolfsii in peanut fields. Plant Dis. Rep. 59:855-858.

15. Sjo, J. 1976. Economics for Agriculturalists: A Beginning Text in Agricultural Economics. Grid, Inc., Columbus, $\mathrm{OH}$.

16. Stansell, J. R., Shepherd, J. L., Pallas, J. E., Bruce, R. R., Minton, N. A., Bell, D. K., and Morgan, L. W. 1976. Peanut responses to soil water variables in the southeast. Peanut Sci. 3:44-48.

17. Staub, T. 1991. Fungicide resistance: Practical experience with antiresistance strategies and the role of integrated use. Annu. Rev. Phytopathol. 29:421-442.

18. Sturgeon, R. V., Jr. 1986. Peanut disease loss estimates for major peanut producing states in the United States for 1984 and 1985. Proc. Am. Peanut Res. Educ. Soc. 18:24-25.

19. Weeks, J. R., Mack, T. P., Hagan, A., Hartzog, D., and Everest, J. W. 1993. Peanut insect, disease, nematode, and weed control recommendations. Ala. Coop. Ext. Ser. Cir. ANR-360. 